\title{
NUMERICAL SIMULATION ON SEISMIC PERFORMANCE OF RETROFITTED MASONRY WALL IN HISTORICAL BUILDINGS DAMAGED IN EARTHQUAKE
}

\author{
BIYE WU ${ }^{1}$, JUNWU DAI ${ }^{1^{*}}$ AND WEN BAI ${ }^{1}$ \\ ${ }^{1}$ Key Laboratory of Earthquake Engineering and Engineering Vibration, \\ Institute of Engineering Mechanics, China Earthquake Administration \\ 29\# Xuefu Road, Harbin, Heilongjiang, China, 150080 \\ e-mail: \{ hit-wby@163.com,jwdai@iem.cn (*corresponding author), \\ 781090853@qq.com \},www.iem.ac.cn
}

Keywords: Earthquake Damaged Wall, Seismic Performance Assessment, External Mortar Layer, External Fibre Layer, Hysteretic Curve.

\begin{abstract}
Due to the characteristics of lower strength, anisotropy, heterogeneity and poor ductility, historical masonry structures usually show poor seismic performance. During earthquakes, the damage severity of masonry structural members varies with their real capacity mostly. To avoid waste and save resources, the following retrofitting strategies would be determined in comply with the cost-effective principles corresponding to the severity level of the damaged buildings. The mechanical properties as to the seismic performance of the critical load bearing walls in the damaged buildings could be improved by retrofitting and repairing. However, how to reasonably and effectively estimate the seismic performance of the retrofitted wall with some level of damage could be the most critical and challengeable point. Based on the finite element analyses, simulation method for the seismic performance of retrofitted masonry wall with damage in earthquake is developed in this paper. The stress and strain hysteretic model for the retrofitted wall element is proposed to consider the three stage effects: original damage, retrofitting or repair, and reloading. According to relevant codes and research results, the damage level of components is classified in terms of the loss level of the axial and shear capacity as well as the deformability. Damage patterns, hysteretic relationships among different retrofitting methods in terms of the external single side of reinforced mortar layer and external single side of fibre reinforced lime mortar layer are compared and analyzed. The seismic capacity and hysteretic skeleton curve of retrofitted masonry wall specimens with different damage levels are developed and discussed. The operational cost-effective retrofitting schemes for masonry walls with different damage levels are proposed.
\end{abstract}

\section{INTRODUCTION}

Historical buildings experienced many destructive uncertainties in their long histories. This results in different degrees of damage and reduced bearing capacity to masonry structures, which makes it difficult to continue to maintain the functionality. The long life of historical architecture makes it have rich cultural mark, which is the mark of architectural history and 
cultural development history. The strength of masonry mortar in most brick masonry historical buildings is relatively low, and the compressive strength of masonry mortar in most brick masonry historical buildings is less than $1.0 \mathrm{MPa}$ or even close to $0.1 \mathrm{MPa}$. At the same time, due to the construction of brick masonry structure and the improper use of lots of reasons historical buildings tend to demonstrate different kind of damage pattern (crisp, mortar pulverization, wall cracks, wall moisture, etc.). These adverse factors weaken the masonry strength and the deformability, thus the structural seismic performance is also decreased.

The painful lessons learned from the Tangshan earthquake in 1976 made Chinese scholars [1-3] paid much attention on the seismic reinforcement of the masonry structures and took a lot of researches on the seismic reinforcement of masonry structures with reinforced (steel mesh) mortar or concrete.

Traditional materials used in masonry structures are mostly brittle with little ductility to resist natural disasters. Based on this point, scholars [4-6] started to study how to reinforce the masonry structures with fibre reinforced materials in lab tests. Carbon fibre and basalt fibre are the most typical fibre reinforced materials in most studies. Strengthening patterns are given priority to use paste fibre cloth. The factors affecting seismic shear bearing capacity of the wall after reinforcement include fibre material properties, paste form, the elastic modulus and compatibility of fibre material, the consolidation time, etc. The results show that the cracking load and ultimate bearing capacity as well as the seismic energy dissipation capacity of the walls are increased to different degrees with factors change

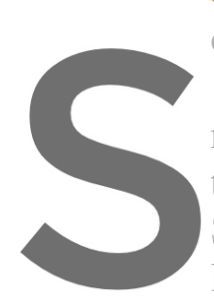

The height of histori relatively low. The rein the method of sticking fibre reinforcement Sticking the fibre can i layer can greatly improve the bearing capacity
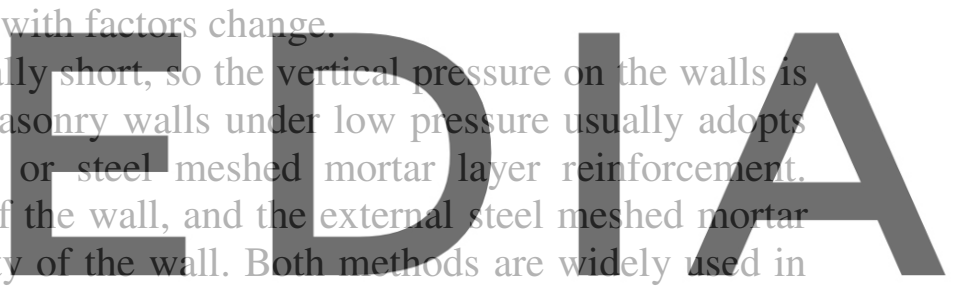

engineering practice, but they are mostly not allowed to use for the brick masonry historical

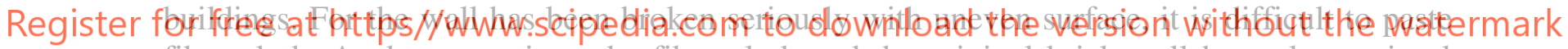
fibre cloth. At the same time, the fibre cloth and the original brick wall has a large visual difference, it is difficult to accept by the architect. After reinforcement with steel meshed mortar layer, the wall stiffness increases, but the wall ductility enhancement effect is not significant. In fact, the original wall is disturbed greatly during construction, and the facade effect is changed after reinforcement, these aspects are all shortcomings for historical masonry structural buildings.

In order to reinforce the brick masonry historic buildings with low strength mortar under low pressure, this paper proposes the method of replacing the steel mesh with natural linen fibre bundles embedded in the external mortar layer. During construction, the cracked wall is firstly repaired with mortar pressure grouting, then pasted with fibre cloth, and finally coated with mortar, the effect is equal to the reinforcement method of the external steel mesh mortar layer. In order to study the adaptability of the traditional mortar strengthening methods to the earthquake damaged brick masonry structure, to determine the usable strength range of masonry mortar for providing sufficient seismic shear bearing capacity after retrofitting, this paper conducted series of numerical analyses about the seismic bearing capacity of damaged low strength masonry walls retrofitted with masonry mortar with strength of $0.4 \mathrm{MPa}$ under axial pressure of $0.3 \mathrm{MPa}$ as example. 


\section{NUMERICAL SPECIMEN MODEL}

\subsection{Specimen design}

Historical buildings have experienced the aging effect of many natural factors such as man-made damage, earthquake damage, differential settlement deformation and freeze-thaw deterioration or temperature deformation etc. during their long service period. Before strengthening the walls of masonry structure historical buildings, it is necessary to investigate the existing damages of the buildings in detail, conduct sample extraction to detect the degradation of materials and evaluate the strength. At the same time, based on the existing degradation status of the buildings and the following usage purpose, appropriate reinforcement methods should be selected based on the principle of repairing the old as old. In this paper, brick walls are divided into five grades: undamaged, slightly damaged, moderately damaged, severely damaged and nearly collapsed according to the degree of bearing capacity loss of the existing buildings. The classification method is shown in Table 1.

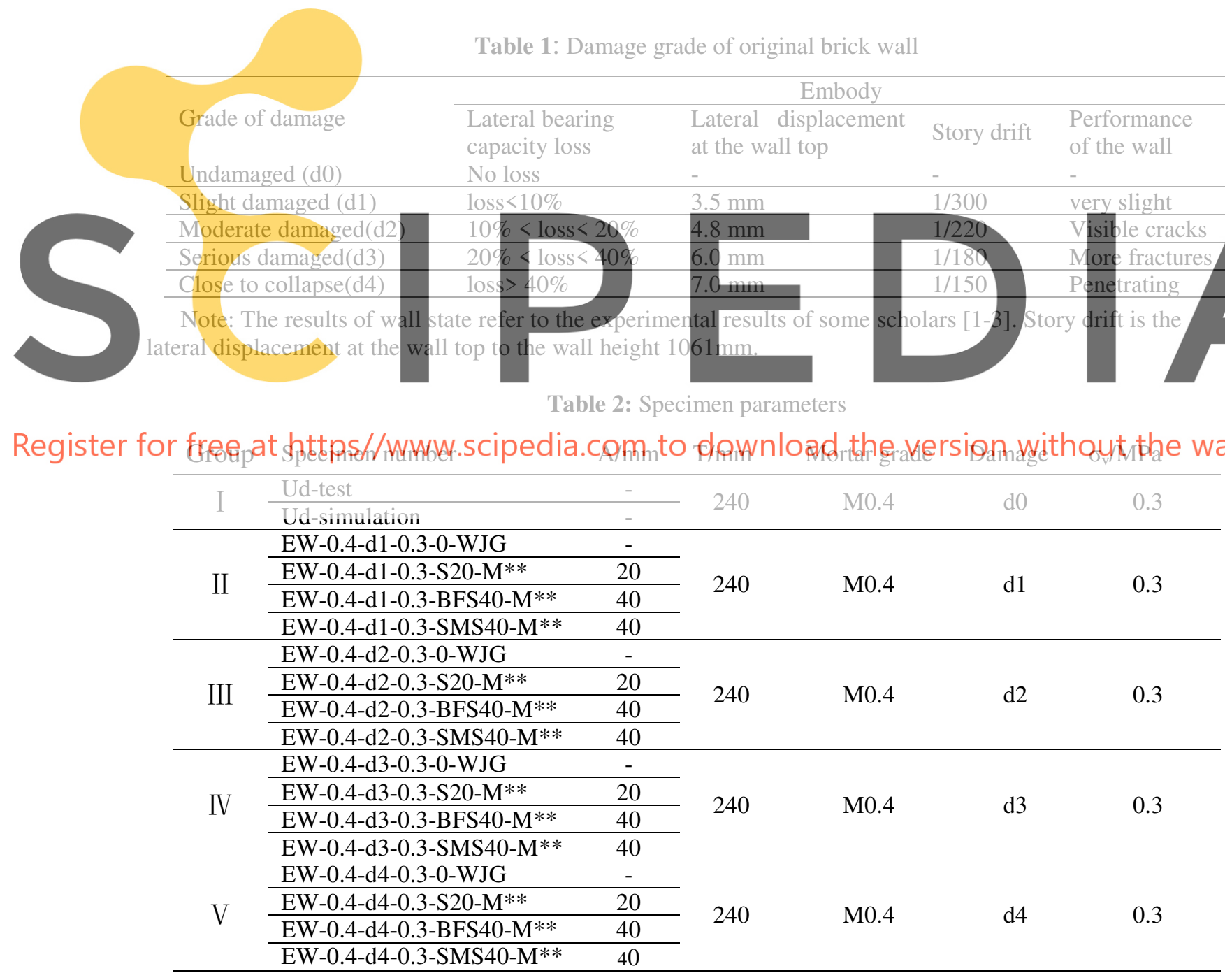

Note: Ud-un damaged wall; $\mathrm{T}$ is wall thickness; $\sigma \mathrm{v}$ is the vertical pressure at the wall top; $\mathrm{A}$ is the thickness of side reinforcement surface layer; S20 is single side $20 \mathrm{~mm}$ lime mortar layer; S40 is single side $40 \mathrm{~mm}$ lime 
mortar layer; BF is the surface layer of fibre bundle mortar; $\mathrm{SM}$ is the surface layer of steel mesh mortar; $\mathrm{M}^{* *}$ is the strength grade of surface mortar, classified as M2.5, M5, M7.5 and M10.

For studying of the reinforcement effect of surface strengthening methods to low strength brick walls in different seismic damage degree and the effect of material degradation caused by the aging and permanent deformation, five groups of 53 specimens of wall are designed in this paper, including one piece of benchmark wall without any damage or any reinforcement, 4 pieces of damaged wall, 16 pieces of single side lime mortar reinforced damaged wall, 16 pieces of single side fibre bundle lime mortar reinforced damaged wall, 16 pieces of single side steel mesh mortar reinforced damaged wall, The parameters of each specimen are shown in Table 2.

In the following study, the specimen size, numerical simulation parameters are same with reference [7], see Fig.1. In the numerical simulation, specimens are strengthened with $20 \mathrm{~mm}$ thick of plain lime mortar surface layer, $40 \mathrm{~mm}$ of reinforced surface layer with $\mathrm{D}=6 \mathrm{~mm} @ 300 \mathrm{~mm}$ steel mesh and same spacing fibre bundles respectively. The fibre bundle area shall be equivalent to the fibre cloth area. The relevant parameters of the reinforcement and fibre bundle materials are shown in Table 3. The strength grade of bricks is MU10 for all specimens, the masonry mortar grade is M0.4 mortar mixed with water, cement and lime, and the external strengthen mortar is M2.5, M5, M7.5 and M10 lime mortar respectively. The strength of materials used in all specimens is shown in Table 3.

Table 3: Strengthening material parameters
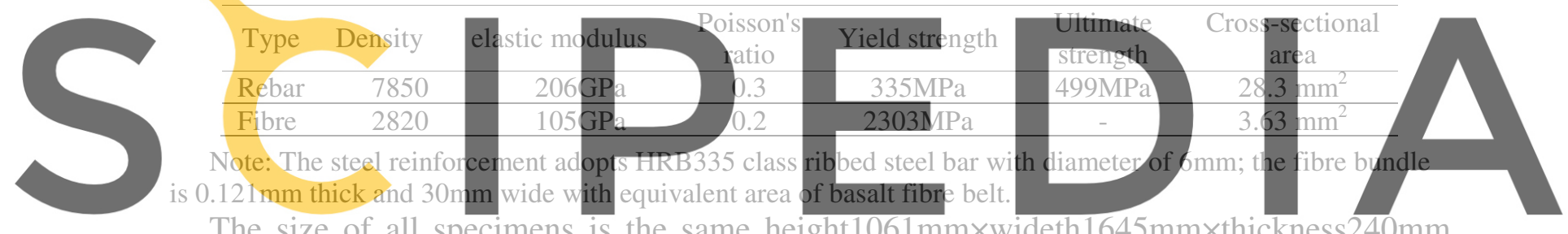

The size of all specimens is the same height1061mm×wideth1645mm×thickness240mm

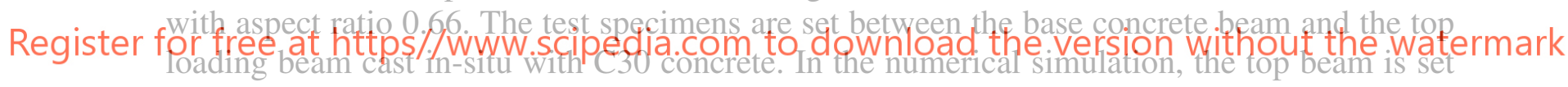
in the model to facilitate load application, and the wall bottom is restrained. The bottom beam is assumed to be the fixed boundary, see Fig. 2.

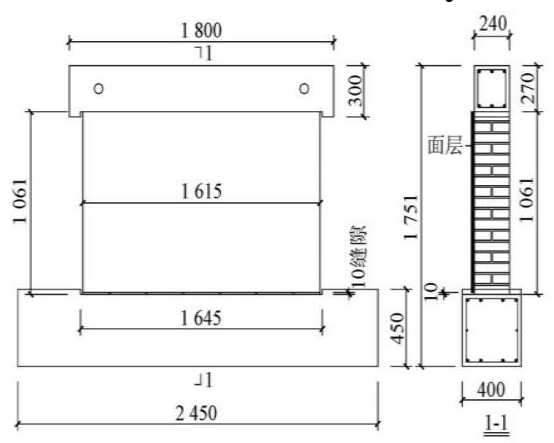

Fig.1. Geometry dimension of the test specimen [7].

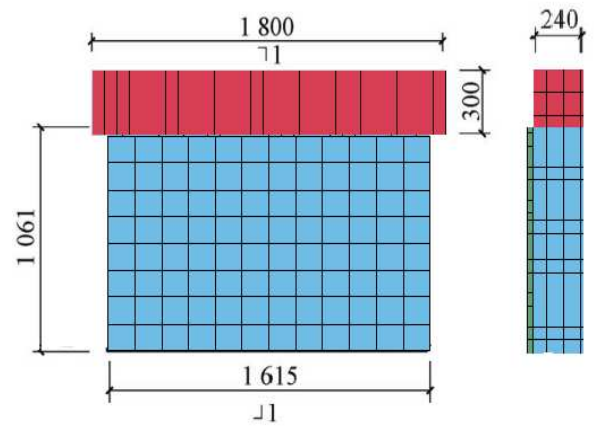

Fig.2. Specimen in numerical simulation

\subsection{Establishment of numerical model}

In this paper, a numerical model is used to study the large deformation behavior of brick masonry walls by using the explicit integration algorithm, and the general large finite element 
software LS-DYNA is used to analyze the bearing capacity and deformation capacity of the unreinforced and reinforced walls. When the numerical model is established, solid elements are used to simulate the brick wall and external mortar layer, while beam elements are used to simulate the fibre bundle and steel mesh. The loading beam and the brick wall are connected by tie elements among surfaces, while the brick wall and the surface mortar are connected by tied nodes.

In the modeling of brick wall materials, mortar and brick blocks are not distinguished and assumed as homogeneous material. The material constitutive model is a double-scalar threeaxis damage constitutive model developed based on the plastic damage mechanics theory in literature [8]. At the same time, the maximum tensile stress theory Rankine (1876) was taken into account in the model, enabling the model to consider permanent deformation in the tensile state. Totally 12 parameters in the constitutive model needs to be determined respectively, including the density $R_{0}$, elastic modulus $E_{0}$, Poisson's ratio $P_{R}$, the ratio of biaxial compression strength to uniaxial compression strength RATIO, tensile strength $\mathrm{F}_{0 \text { t, }}$ compressive yield strength $\mathrm{F}_{0 \mathrm{c}}$, plastic flow constant Beta, fracture energy $\mathrm{G}_{\mathrm{F}}$, compression damage evolution equation model parameters $\mathrm{A}_{c}$ and $\mathrm{B}_{\mathrm{c}}$, tensile damage evolution equation model parameters $A_{t}$, same with references [8-11], shown in Table 4. When the maximum tensile stress of the element exceeds $\mathrm{F}_{0 \mathrm{t}}$ or the maximum compressive strain exceeds 0.0023 , the element is considered to be failed.

Table 4: Constitutive model parameters of brick block materials
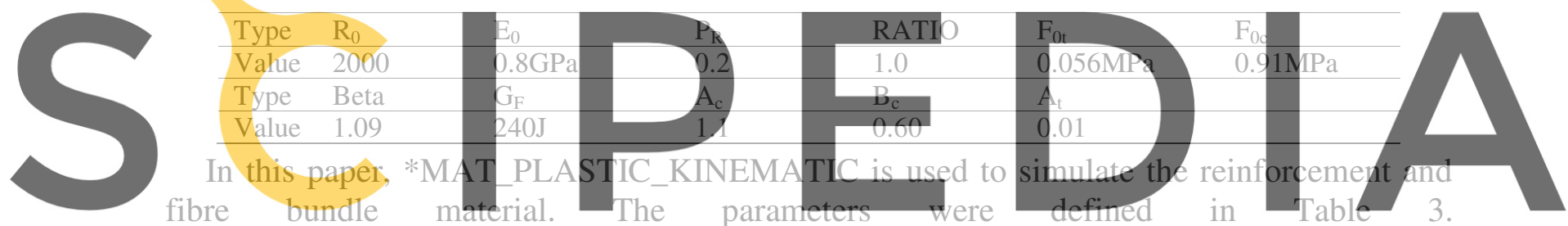

The*MAT_CONCRETE_DAMAGE_REL3 material in the finite element software library is

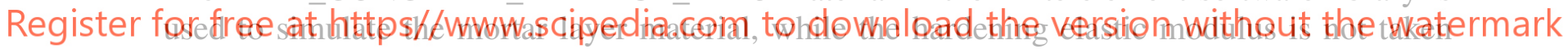
into account. When the maximum compressive strain of the element reaches 0.0033 or the main tensile stress, it is considered to be invalid, in which the main tensile stress is $1 / 10$ of the compressive strength of the mortar.

\subsection{Establishment of damage mechanism and loading system}

Masonry is one kind of the most important structural materials in construction of historical buildings. In fact, structural masonry walls in historical buildings usually experience a long term deterioration in strength, stiffness as well as bearing capacity caused by aging, erosion or even kinds of natural or mankind damages. As matter of fact, existing stress and strain usually remains at a certain level in the original parts of the retrofitted wall, while the latterly attached new parts especially the externally reinforced mortar layer in retrofitting usually can't share vertical loads with the original wall together immediately after the retrofitting construction if there were no new deformation or loading condition change of the retrofitted structure. Using full restart analysis function in the finite element analyses, the above concern could be solved. Full restart analysis is a continuation of the previous analysis. When restarted, latterly attached parts could be added correspondingly. In the full restart analysis, the first step is to 
load damage to the wall, the second step is to retrofit the damaged wall, and then to restart analysis, the original part of the model to read the results of the first step for stress initialization. The entire analysis process is shown in the Fig.3.

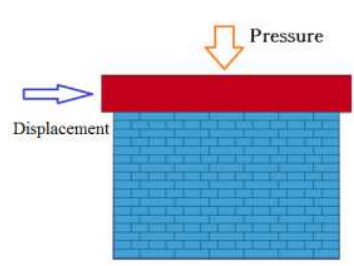

(a) Wall pre-damage

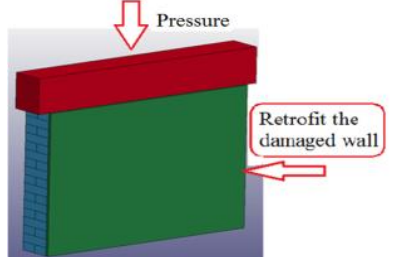

(b) Reinforcement

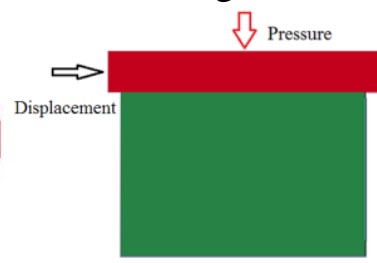

(c) Restart loading

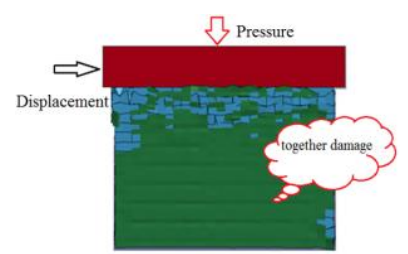

(d) Together destroyed

Fig.3. Reinforcement analysis procedure with completely restart in numerical simulation.

In the numerical simulation, the "displacement loading" protocol is used to for all specimens. As well, a $0.3 \mathrm{MPa}$ constant vertical pressure is applied on the beam top of the wall, and simultaneously a horizontal low cycle concentrated load is applied to the load beam

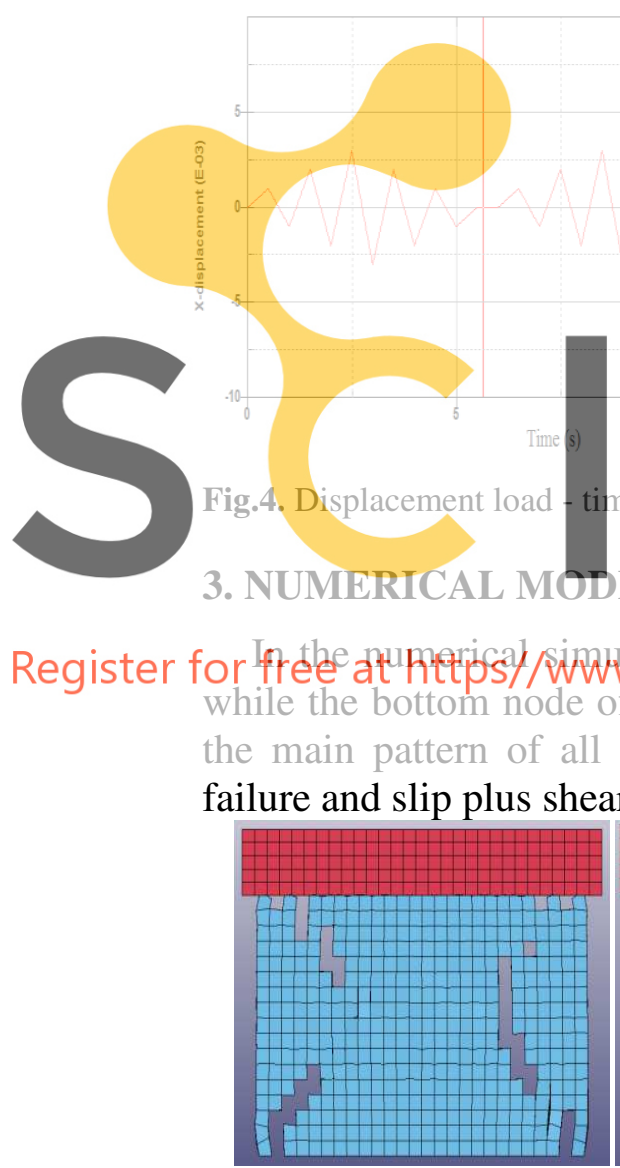

on top of the wall specimen. Starting from the first stage of cyclic load with displacement of \pm $1 \mathrm{~mm}$, each cycle increases by $1 \mathrm{~mm}$ step by step, and the load of each stage repeats once. The displacement load protocol is shown in Fig.4, where 0-6 seconds is the pre-damage loading duration, and 6-16 seconds is the loading

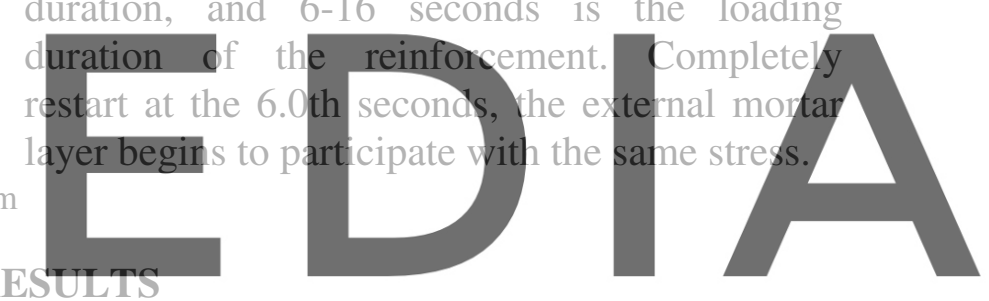

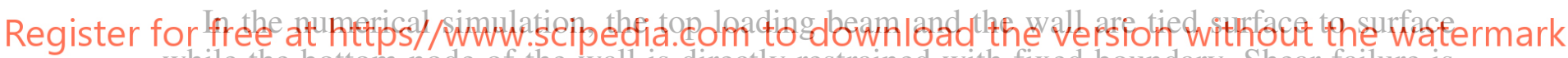
while the bottom node of the wall is directly restrained with fixed boundary. Shear failure is the main pattern of all wall specimens together with loading beam slip, wall bottom slip failure and slip plus shear failure, as shown in Fig. 5.

(a) Wall shear failure

(b) Loading beam slip failure

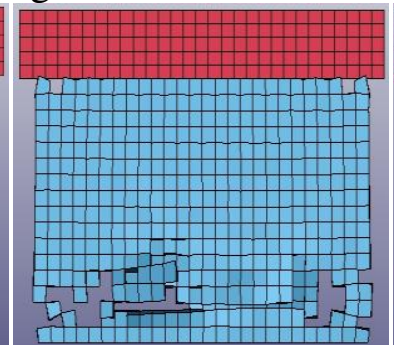

(c) Wall bottom slip failure

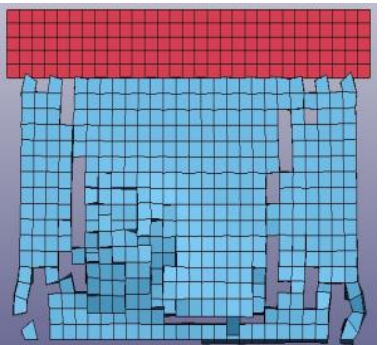

(d) Slip + shear failure

Fig.5. Failure pattern of wall specimen

The analysis results of 53 wall reinforcement specimens show that the damage of the internal original part of brick wall is still the main failure pattern, and most specimens can sustain the load bearing capacity even when the external mortar layer collapse, only partial spalling or severe cracks. Brick wall damage mainly demonstrates as above four patterns shown in fig.5, the only difference is the shape and size of cracks. 


\subsection{Single side reinforcement with $20 \mathrm{~mm}$ lime mortar layer}

In the numerical simulation, equivalent material grade M0.4 is used to simulate the original masonry wall. All models are preloaded to form the initial conditions corresponding to different damage levels, and then strengthened with the single side of $20 \mathrm{~mm}$ lime mortar layer in four strength levels of M2.5, M5, M7.5 and M10. The test results are shown in Table 4.Due to the paper space limitation, only failure patterns are demonstrated here, as shown in Fig.6. It can be seen that the X-type shear failure is the main pattern for the original wall both in lab experiment and numerical simulation.

Results in Table 4 shows that: For wall with strength grade of M0.4, in case of the single side of $20 \mathrm{~mm}$ lime mortar layer is used for reinforcement, the deformability of the original wall is enhanced by about $20 \%$ at the slight damage level, while the horizontal ultimate bearing capacity of the wall is not increased. Considering the perspective of residual bearing capacity, M5 is the best. Compared with the unreinforced damaged wall, the deformability of M5 wall used for the external mortar layer is enhanced by about 20\% corresponding to the moderate damage level of the original wall, and the residual bearing capacity before collapse is higher. Corresponding to the severe damage level of the original wall, the mortar layer with various strengths all can enhance the deformability by about $25 \%-30 \%$. The residual bearing capacity of the external mortar layer before M5 collapse is relatively high. When the original wall is close to collapse, the effect of the external mortar layer reinforcement on the deformability and horizontal ultimate bearing capacity of the wall is not obvious.
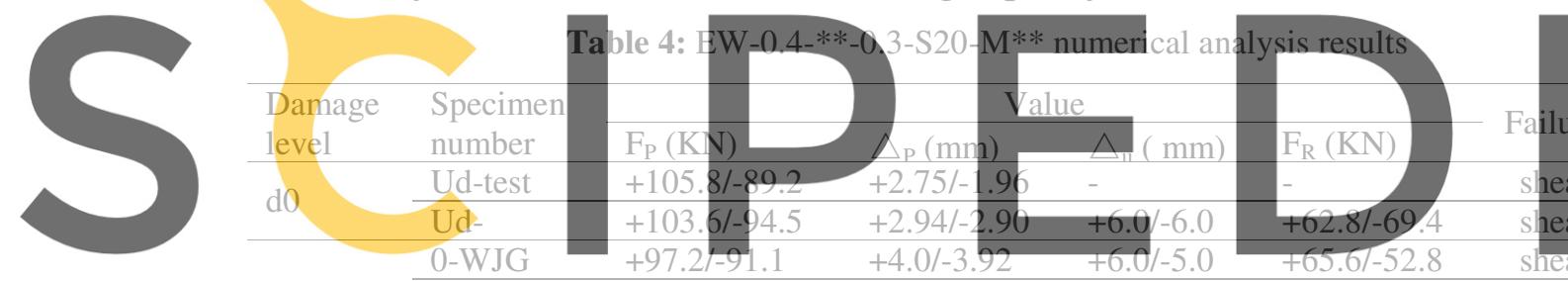

S20-M2.5

$+97.6 /-95.8+3.9 /-3.95$

$+6.2 /-5.7$

$+74.1 /-43.8$

shear failure

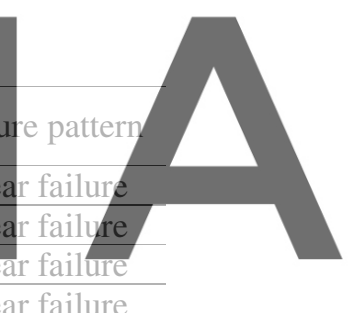

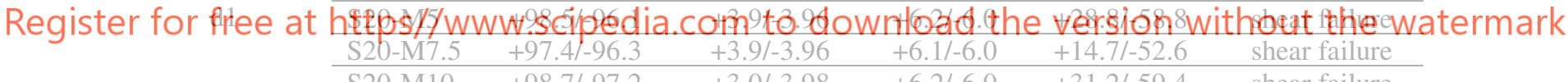

\begin{tabular}{|c|c|c|c|c|c|c|}
\hline & S20-M10 & $+98.7 /-97.2$ & $+3.0 /-3.98$ & $+6.2 /-6.0$ & $+31.2 /-59.4$ & shear failure \\
\hline \multirow{5}{*}{ d2 } & $0-\mathrm{WJG}$ & $+90.3 /-85.5$ & $+3.0 /-3.93$ & $+6.0 /-5.0$ & $+59.1 /-36.9$ & shear failure \\
\hline & S20-M2.5 & $+93.0 /-85.7$ & $+3.0 /-3.98$ & $+6.0 /-5.8$ & $+60.8 /-40.2$ & shear failure \\
\hline & S20-M5 & $+94.6 /-89.7$ & $+3.0 /-3.98$ & $+6.0 /-6.0$ & $+71.6 /-49.5$ & shear failure \\
\hline & S20-M7.5 & $+94.9 /-84.8$ & $+3.0 /-3.90$ & $+6.0 /-6.0$ & $+66.9 /-56.8$ & shear failure \\
\hline & S20-M10 & $+95.3 /-89.1$ & $+3.0 /-3.99$ & $+6.0 /-6.0$ & $+66.4 /-49.2$ & shear failure \\
\hline \multirow{5}{*}{$\mathrm{d} 3$} & $0-\mathrm{WJG}$ & $+71.0 /-64.4$ & $+2.9 /-3.0$ & $+5.0 /-5.0$ & $+64.8 /-60.3$ & shear failure \\
\hline & S20-M2.5 & $+76.5 /-71.1$ & $+3.9 /-3.95$ & $+5.0 /-5.0$ & $+62.6 /-42.3$ & shear failure \\
\hline & S20-M5 & $+76.4 /-73.6$ & $+3.0 /-3.94$ & $+5.0 /-5.0$ & $+63.6 /-42.2$ & shear failure \\
\hline & S20-M7.5 & $+76.6 /-74.2$ & $+3.0 /-3.99$ & $+5.2 /-5.0$ & $+27.8 /-41.1$ & shear failure \\
\hline & S20-M10 & $+76.8 /-75.8$ & $+3.9 /-3.7$ & $+5.2 /-5.0$ & $+39.3 /-46.8$ & shear failure \\
\hline \multirow{5}{*}{$\mathrm{d} 4$} & $0-\mathrm{WJG}$ & $+60.0 /-55.4$ & $+2.9 /-3.90$ & $+4.0 /-4.0$ & $+41.0 /-50.1$ & shear failure \\
\hline & S20-M2.5 & $+61.3 /-52.4$ & $+3.0 /-3.94$ & $+4.3 /-4.0$ & $+32.2 /-51.2$ & shear failure \\
\hline & S20-M5 & $+61.1 /-54.3$ & $+3.0 /-3.99$ & $+4.3 /-4.0$ & $+32.5 /-53.3$ & shear failure \\
\hline & S20-M7.5 & $+65.3 /-52.3$ & $+3.0 /-4.0$ & $+4.6 /-4.0$ & $+38.7 /-49.6$ & shear failure \\
\hline & S20-M10 & $+63.2 /-56.8$ & $+3.0 /-3.94$ & $+5.0 /-4.2$ & $+41.2 /-20.6$ & shear failure \\
\hline
\end{tabular}

Note: Ud-un damaged wall, FP - horizontal ultimate bearing capacity of wall, $\triangle \mathrm{P}$ - displacement corresponding to the horizontal ultimate bearing capacity, $\triangle \mathrm{u}$ - refers to the wall's ultimate displacement value, FR-wall residual bearing capacity, that is the peak bearing capacity before the ultimate displacement of the wall. 


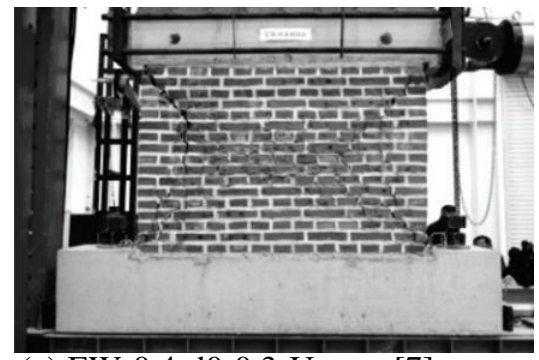

(a) EW-0.4-d0-0.3-U $\mathrm{d}_{\mathrm{d}}$-test [7]

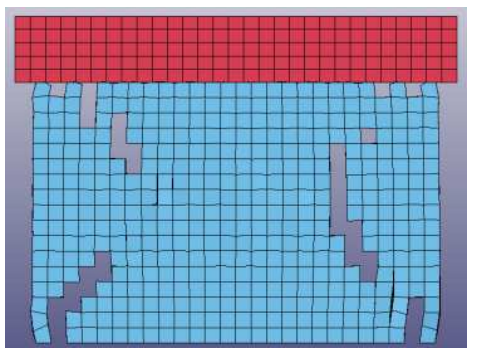

(b) EW-0.4-d0-0.3-U $\mathrm{U}_{\mathrm{d}}$-simulation

Fig.6. The failure pattern in numerical simulation and failure pattern lab test

For brick walls with masonry mortar grade of M0.4 and top pressure of $0.3 \mathrm{MPa}$, when a single side of $20 \mathrm{~mm}$ lime mortar layer is used for reinforcement, the attached mortar layer has little effect on the horizontal ultimate bearing capacity of the wall, but it can improve the deformability of the wall obviously. When the damage level is $\mathrm{d} 1-\mathrm{d} 3$, the most compatible mortar strength grade is M5. When the damage level is d4, the effect of strengthening with a single side of $20 \mathrm{~mm}$ lime mortar layer on the deformability is very weak, so the single side of $20 \mathrm{~mm}$ mortar layer reinforcement method is not recommended for this damage level.

\subsection{Single side of $\mathbf{4 0} \mathrm{mm}$ fibre bundle lime mortar layer reinforcement}

The brick wall specimens with M0.4 masonry mortar reinforced with single side of $40 \mathrm{~mm}$ fibre bundle lime mortar layer are numerically simulated in this part. The mortar strength is

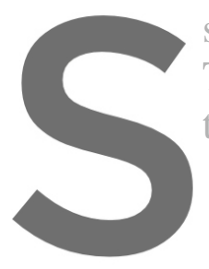
set with grades of M2.5,
Table 5, the load-displace
the skeleton curve of the
Tab level number
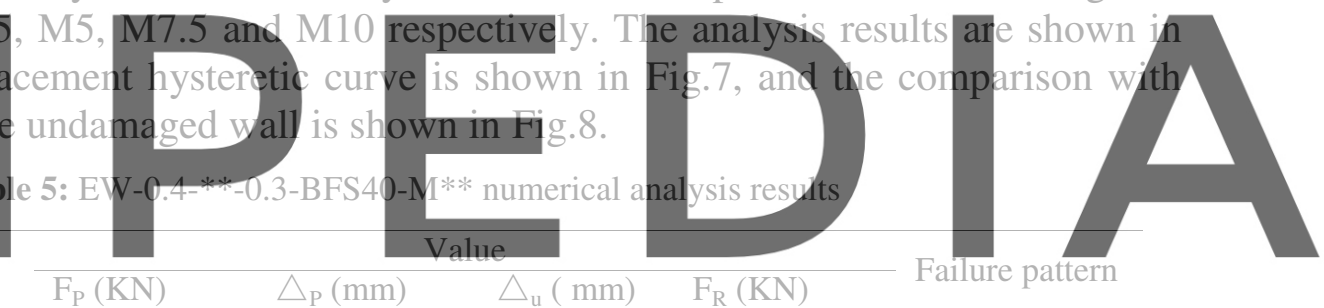

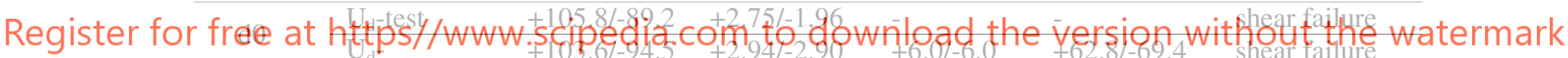

\begin{tabular}{|c|c|c|c|c|c|c|}
\hline \multirow{5}{*}{ d1 } & $0-\mathrm{WJG}$ & $+97.2 /-91.1$ & $+4.0 /-3.92$ & $+6.0 /-5.0$ & $+65.6 /-52.8$ & shear failure \\
\hline & BFS40-M2.5 & $+104.1 /-101$ & $+3.2 /-3.7$ & $+7.0 /-7.0$ & $+59.2 /-21.3$ & shear failure \\
\hline & BFS40-M5 & $+104.3 /-101$ & $+4.0 /-2.9$ & $+7.0 /-7.0$ & $+48.8 /-45.6$ & shear failure \\
\hline & BFS40-M7.5 & $+104.3 /-103$ & $+2.9 /-3.4$ & $+8.0 /-7.0$ & $+24.6 /-51.6$ & shear failure \\
\hline & BFS40-M10 & $+103 /-111$ & $+2.0 /-3.5$ & $+8.0 /-7.0$ & $+47.2 /-70.1$ & shear failure \\
\hline \multirow{5}{*}{$\mathrm{d} 2$} & 0-WJG & $+90.3 /-85.5$ & $+3.0 /-3.93$ & $+6.0 /-5.0$ & $+59.1 /-36.9$ & shear failure \\
\hline & BFS40-M2.5 & $+97.3 /-89.3$ & $+3.0 /-4.0$ & $+7.0 /-6.0$ & $+33.1 /-65.4$ & shear failure \\
\hline & BFS40-M5 & $+101 /-89.9$ & $+3.0 /-3.7$ & $+7.0 /-7.0$ & $+54.4 /-16.1$ & shear failure \\
\hline & BFS40-M7.5 & $+102 /-91.6$ & $+3.6 /-4.0$ & $+7.0 /-7.0$ & $+55.1 /-27.1$ & shear failure \\
\hline & BFS40-M10 & $+103 /-98.2$ & $+3.0 /-3.7$ & $+7.0 /-7.0$ & $+50.2 /-31.6$ & shear failure \\
\hline \multirow{5}{*}{ d3 } & $0-\mathrm{WJG}$ & $+71.0 /-64.4$ & $+2.9 /-3.0$ & $+5.0 /-5.0$ & $+64.8 /-60.3$ & shear failure \\
\hline & BFS40-M2.5 & $+78.5 /-76.2$ & $+3.0 /-3.0$ & $+6.0 /-6.0$ & $+41.7 /-20.1$ & shear failure \\
\hline & BFS40-M5 & $+80.0 /-80.3$ & $+3.3 /-3.0$ & $+6.0 /-6.0$ & $+58.6 /-43.9$ & shear failure \\
\hline & BFS40-M7.5 & $+81.4 /-80.0$ & $+3.0 /-3.0$ & $+6.0 /-6.0$ & $+57.7 /-50.2$ & shear failure \\
\hline & BFS40-M10 & $+81.5 /-80.0$ & $+3.0 /-3.1$ & $+6.0 /-6.0$ & $+58.4 /-43.9$ & shear failure \\
\hline \multirow{5}{*}{$\mathrm{d} 4$} & $0-\mathrm{WJG}$ & $+60.0 /-55.4$ & $+2.9 /-3.90$ & $+4.0 /-4.0$ & $+41.0 /-50.1$ & shear failure \\
\hline & BFS40-M2.5 & $+7.9 /-66.8$ & $+2.9 /-3.7$ & $+6.0 /-5.0$ & $+21.5 /-47.6$ & shear failure \\
\hline & BFS40-M5 & $+70.7 /-60.5$ & $+3.0 /-3.4$ & $+6.0 /-5.0$ & $+45.0 /-54.9$ & shear failure \\
\hline & BFS40-M7.5 & $+69.1 /-53.8$ & $+2.9 /-3.2$ & $+6.0 /-5.0$ & $+42.7 /-22.5$ & shear failure \\
\hline & BFS40-M10 & $+74.7 /-63.6$ & $+3.0 /-3.5$ & $+6.0 /-5.0$ & $+34.9 /-56.6$ & shear failure \\
\hline
\end{tabular}


The analysis results in Table 5 show that for brick walls with masonry mortar strength level of $0.4 \mathrm{MPa}$, the failure mode of all wall specimens remains unchanged and remains shear failure even reinforced with single side of $40 \mathrm{~mm}$ fibre bundle lime mortar layer. In a variety of damage states, the bearing capacity and deformability of the wall are enhanced after reinforcement, but not significantly increased with the mortar strength increasing. Also, the M5 grade lime mortar can be considered for reinforcement.
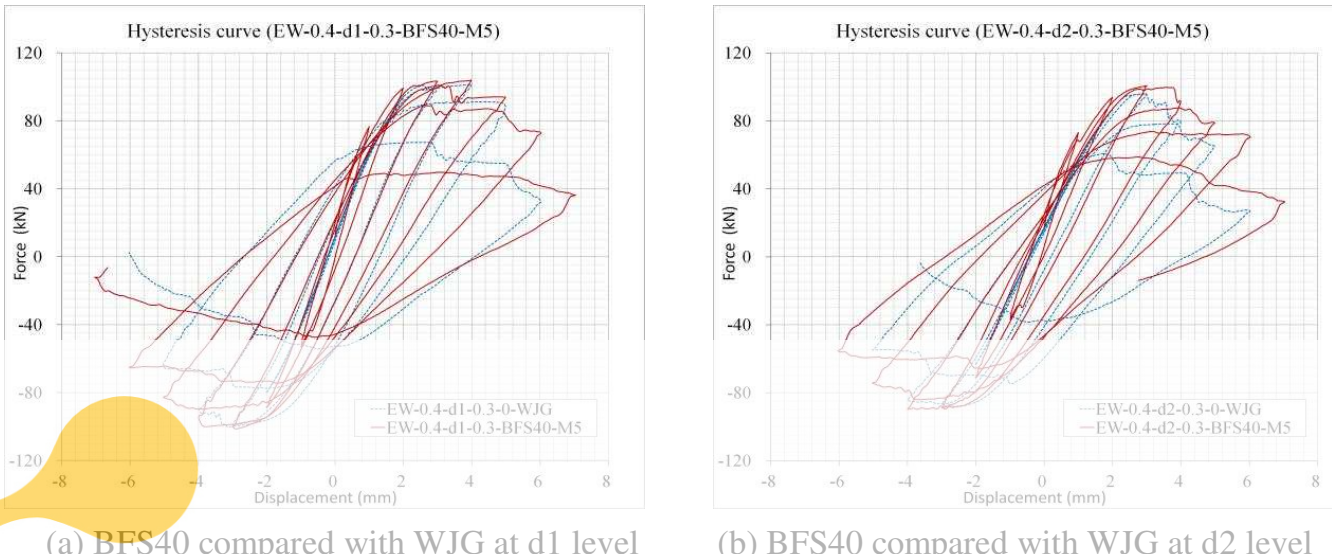

(b) BFS40 compared with WJG at d2 level

Fig.7. Load-displacement hysteretic curve of single side of $40 \mathrm{~mm}$ fibre bundle lime mortar reinforcement

Fig.7 shows the strengthening effect of single $40 \mathrm{~mm}$ fibre bundle lime mortar layer reinforcement. Compared with the unreinforced damage original wall strengthen ultimate bearing capaci at the moderate damage by M5 lime mortar increased by about $15-40 \%$ of the wall increased by about $14 \%$.

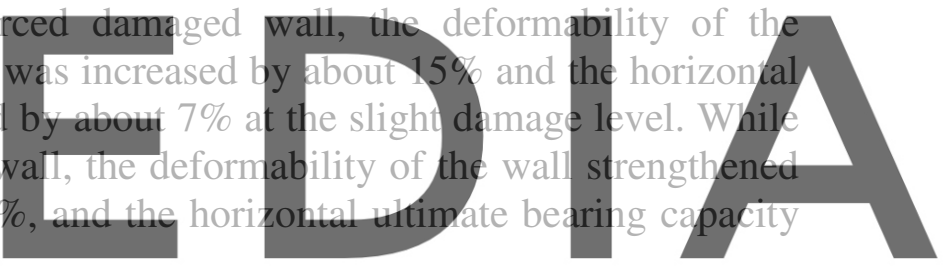

Register for free ${ }^{20}$ at https//WWW.SCipedja.com to download the version. Without the watermark

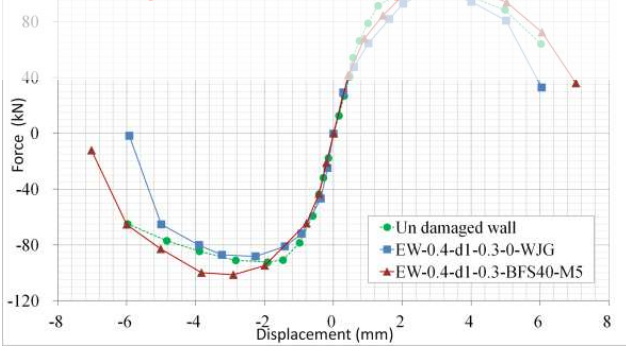

(a) BFS40 compared with WJG at d1 level

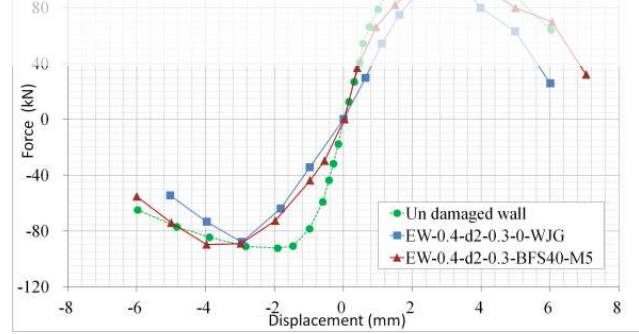

(b) BFS40 compared with WJG at d2 level

Fig.8. Skeleton curve of single side of $40 \mathrm{~mm}$ fibre bundle lime mortar reinforcement

As can be seen from Fig.8, for the damaged wall strengthened by the external layer of single side of $40 \mathrm{~mm}$ fibre bundles lime mortar, if the original wall is slightly damaged and generally damaged, M5 lime mortar is adopted to reinforce the wall, the horizontal ultimate bearing capacity and deformability of the wall can be restored to the level before the damage.

\subsection{Single side of $40 \mathrm{~mm}$ steel mesh lime mortar layer reinforcement}

Similarly, in this part the brick wall specimens are all set with M0.4 masonry mortar and 
strengthened with external single side of $40 \mathrm{~mm}$ steel mesh lime mortar layer. The mortar grades also uses grade of M2.5, M5, M7.5 and M10 respectively. The corresponding analytical results are shown in Table 6, the comparison with the skeleton curve of the undamaged wall is shown in Fig.9.

Table 6: EW-0.4-**-0.3-SMS40-M** numerical analysis results

\begin{tabular}{|c|c|c|c|c|c|c|}
\hline \multirow{2}{*}{$\begin{array}{l}\text { Damage } \\
\text { level }\end{array}$} & \multirow{2}{*}{$\begin{array}{l}\text { Specimen } \\
\text { number }\end{array}$} & \multicolumn{4}{|l|}{ Value } & \multirow{2}{*}{$\begin{array}{l}\text { Failure } \\
\text { pattern }\end{array}$} \\
\hline & & $\mathrm{F}_{\mathrm{P}}(\mathrm{KN})$ & $\triangle \mathrm{P}(\mathrm{mm})$ & $\triangle \mathrm{u}(\mathrm{mm})$ & $\mathrm{F}_{\mathrm{R}}(\mathrm{KN})$ & \\
\hline \multirow{2}{*}{$\mathrm{d} 0$} & Ud-test & $+105.8 /-89.2$ & $+2.75 /-1.96$ & - & - & shear failure \\
\hline & Ud-simulation & $+103.6 /-94.5$ & $+2.94 /-2.90$ & $+6.0 /-6.0$ & $+62.8 /-69.4$ & shear failure \\
\hline \multirow{5}{*}{ d1 } & $0-\mathrm{WJG}$ & $+97.2 /-91.1$ & $+4.0 /-3.92$ & $+6.0 /-5.0$ & $+65.6 /-52.8$ & shear failure \\
\hline & SMS40-M2.5 & $+105 /-103$ & $+3.7 /-2.8$ & $+7.0 /-7.0$ & $+58.7 /-30.9$ & shear failure \\
\hline & SMS40-M5 & $+105.3 /-$ & $+3.9 /-3.0$ & $+7.0 /-7.0$ & $+57.3 /-68.2$ & shear failure \\
\hline & SMS40-M7.5 & $+107 /-105$ & $+4.0 /-3.0$ & $+7.0 /-7.0$ & $+41.6 /-65.8$ & shear failure \\
\hline & SMS40-M10 & $+112.2 /-110$ & $+4.0 /-3.7$ & $+7.0 /-7.0$ & $+46.2 /-68.0$ & shear failure \\
\hline \multirow{14}{*}{$\mathrm{d} 2$} & $0-\mathrm{WJG}$ & $+90.3 /-85.5$ & $+3.0 /-3.93$ & $+6.0 /-5.0$ & $+59.1 /-36.9$ & shear failure \\
\hline & SMS40-M2.5 & $+98.7 /-92.3$ & $+3.0 /-3.0$ & $+7.0 /-7.0$ & $+60.8 /-21.9$ & shear failure \\
\hline & SMS40-M5 & $+101.4 /-93.0$ & $+2.9 /-3.0$ & $+7.0 /-7.0$ & $+74.5 /-44.4$ & shear failure \\
\hline & SMS40-M7.5 & $+104 /-95.7$ & $+3.0 /-4.0$ & $+7.0 /-7.0$ & $+71.5 /-54.7$ & shear failure \\
\hline & SMS40-M10 & $+106 /-96.4$ & $+3.0 /-4.0$ & $+7.0 /-7.0$ & $+66.6 /-53.5$ & shear failure \\
\hline & $0-\mathrm{WJG}$ & $+71.0 /-64.4$ & $+2.9 /-3.0$ & $+5.0 /-5.0$ & $+64.8 /-60.3$ & shear failure \\
\hline & SMS40-M2.5 & $+78.9 /-75.2$ & $+3.0 /-3.0$ & $+6.0 /-6.0$ & $+57.2 /-35.1$ & shear failure \\
\hline & SMS40-M5 & $+82.7 /-87.4$ & $+3.3 /-4.0$ & $+6.0 /-6.0$ & $+36.9 /-62.9$ & shear failure \\
\hline & SMS40-M7.5 & $+82.5 /-82.1$ & $+3.0 /-3.0$ & $+6.0 /-6.0$ & $+66.6 /-52.6$ & shear failure \\
\hline & SMS40-M10 & $+83.6 /-82.1$ & $+3.0 /-3.2$ & $+6.0 /-6.0$ & $+60.3 /-61.6$ & shear failure \\
\hline & O-WJG & -55.2 & & -4.0 & & shear failure \\
\hline & $\begin{array}{l}\text { SMS40-M2. } \\
\text { SMS40-M5 }\end{array}$ & $\frac{/-62.1}{t-61.4}$ & $+5.01-$ & -5.0 & $\begin{array}{l}+58.3 /-53.7 \\
+41.2 /-55 .\end{array}$ & ailure \\
\hline & SMS40-M7.. & $31-65.3$ & $+3.0 /-4.0$ & $+6.0 /-6.0$ & $+45.9 /-47.6$ & (9- \\
\hline & SMS40-M10 & $+73.0 /-66.8$ & $+3.0 /-3.4$ & $+6.0 /-6.0$ & $-51.9 /-32.8$ & $=$ \\
\hline
\end{tabular}

Note: The related variables in the table have the same meaning as in Table 4

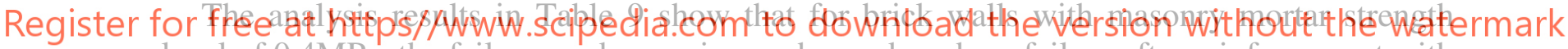
level of $0.4 \mathrm{MPa}$, the failure mode remains unchanged as shear failure after reinforcement with single side of $40 \mathrm{~mm}$ steel mesh lime mortar layer. At all damage level, the bearing capacity and deformability of the wall are enhanced. The higher the strength of the mortar used in wall reinforcement, the more significant the growth of the deformability and the bearing capacity.

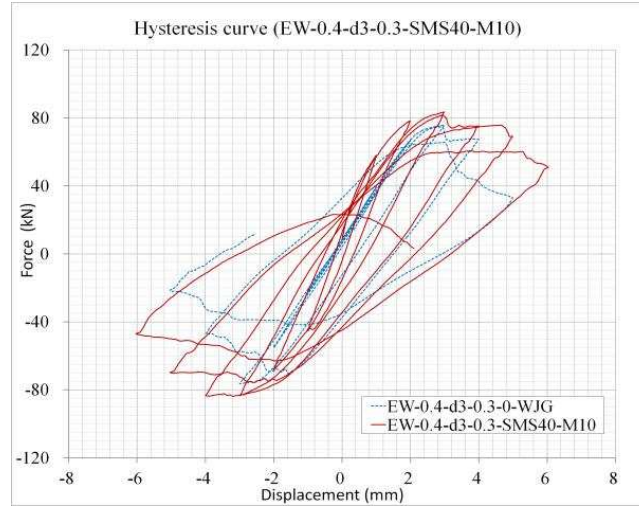

(a) SMS40 compared with WJG at d3 level

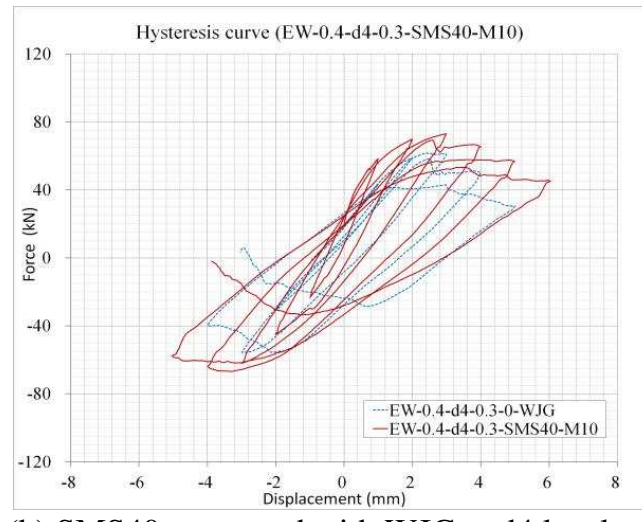

(b) SMS40 compared with WJG at d4 level

Fig.9. Load-displacement hysteretic curve of single side of $40 \mathrm{~mm}$ steel mesh lime mortar reinforcement 
Fig.10 shows the strengthening effect of single side of $40 \mathrm{~mm}$ steel mesh lime mortar reinforcement. Compared with the unreinforced damaged wall, When the original wall was seriously damaged, the deformability of the wall was strengthened with M10 lime mortar increased by about $20 \%$, and the horizontal ultimate bearing capacity increased by about $27.5 \%$. When the original wall was close to collapse, the deformability of the wall strengthened by M10 lime mortar increased by nearly $50 \%$, and the horizontal ultimate bearing capacity increased by about $21.7 \%$.

It can be concluded from the comparative analysis in Fig.10 that for the damaged wall strengthened by the external single $40 \mathrm{~mm}$ steel mesh mortar layer, when the strength of mortar is M10, the bearing capacity can reach or even exceed the bearing capacity of the wall before the damage, and the deformability can be increased by about $15 \%$. Under the condition of severe damage or close to collapse, the horizontal ultimate bearing capacity of the reinforced wall can reach $70-80 \%$ of the horizontal ultimate bearing capacity of the wall before the damage, and the deformability can reach that of the wall before the damage.

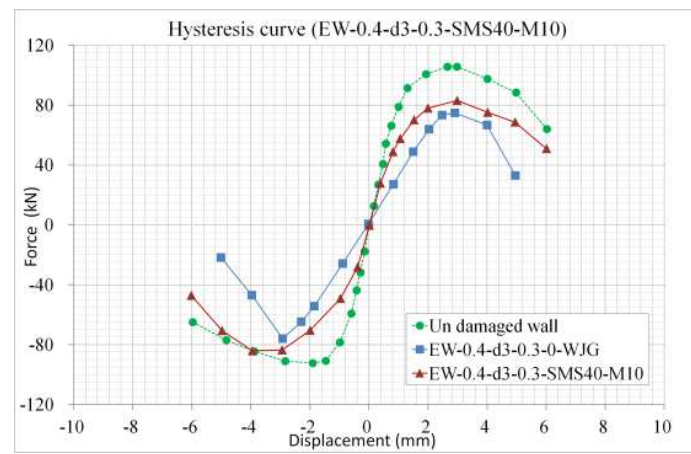

(a) SMS40 compared with WJG at d3 level

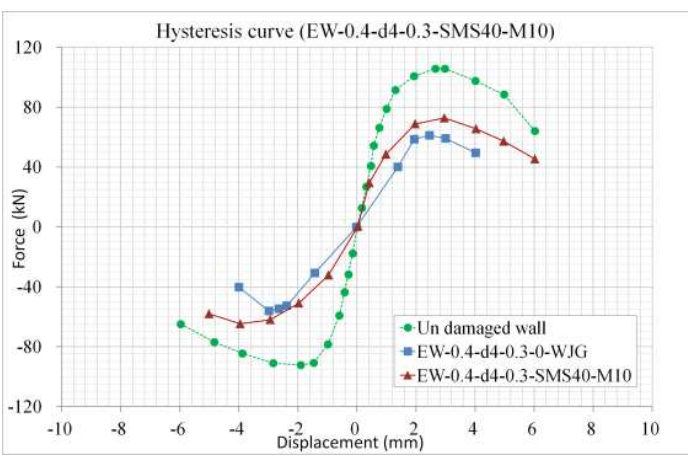

(b) SMS40 compared with WJG at d4 level

Fig.10. Skeleton curve of single side of $40 \mathrm{~mm}$ steel mesh lime mortar reinforcement

\section{CONCLUSIONS}

The brick masonry historical buildings are usually experience unexpected degradation and conditions of the critical load bearing walls are complex. When choosing proper reinforcement method, extensive investigations and tests should be conducted in considering of the history and current situation of the building, so as to clarify the damage state of the walls, and appropriate reinforcement methods should be selected in combination with the architectural features.

From above studies, it can be seen that for the brick masonry historic buildings with weathered and damaged surface, its deformability can be improved using the single side of 20 mm M5 lime mortar.

For the brick masonry walls with slight damage and moderate damage in historical buildings, the single side of $40 \mathrm{~mm}$ lime mortar layer can be used for reinforcement, and the reinforcement materials inside the mortar can be fibre bundle or steel mesh. When the fibre bundle is used as the reinforcement material, the mortar strength should be selected as M5, and the horizontal ultimate bearing capacity and deformability of the wall can be restored to the pre-damage level with the reinforcement. When steel mesh is used as reinforcement material, the strength grade of mortar can be selected as M10, the horizontal ultimate bearing 
capacity of the wall can exceed the bearing capacity of the wall before damage, and the deformability can be enhanced by about $10 \%$.

In the reinforcement and repair of historical buildings, for walls with serious damage or is close to collapse, the effect of strengthening the bearing capacity and deformation capacity of the wall by fiber bundle is not significant. When reinforced steel mesh is used as the reinforcement material, for the wall with severe damage, the bearing capacity of the reinforced wall can reach $81 \%$ that of the intact wall. The deformability can reach $100 \%$ that of the intact wall. For a severe damaged wall which is close to collapse, the bearing capacity of the reinforced wall can reach $70 \%$ that of the intact wall. The deformability can reach $100 \%$ that of the intact wall.

Acknowledgements. This work is supported by the national key research and development plan "major natural disasters monitoring, early warning and prevention" special project of 2018 (2018YFC1504400).

\section{REFERENCES}

[1] Zhu Bolong, Wu Mingshun, Jiang Zhixian. A study on seismic capacity of brick wall strengthened with cement mortar reinforced with steel mesh [J]. Earthquake Engineering and Engineering Vibration, 1984, 4(1):70-81.

[2] Huang Zhongbang. The study on adopting the cover with cement mortar and the cover with reinforced cement mortar to strengthen brick masonry [J]. Journal of Tianjin University, 1994, 27(6):764-770.

[3] Liming, Wang Zhihao. Experimental research on masonry wall with low-strength mortar strengthened with steel-mesh cement mortar [J]. Building Structures, 2003, 33(10):34-36.

[4] Triantafillou T C, Fardis M N. Strengthening of historic masonry structures with composite materials [J]. Materials and Structures, 1997, 30(8):486-496.

[5] Kuzik M D, Elwi A E, Cheng J J R. Cyclic Flexure Tests of Masonry Walls Reinforced with Glass Fibre Reinforced Polymer Sheets [J]. Journal of Composites for Construction, 2003, 7(1):20-30.

[6] Jing M, Raongjant W. Experimental Study on Historic Masonry Walls Retrofitted with GFRP Sheets in Different Patterns [J]. Applied Mechanics and Materials, 2015, 723:377-381.

[7] Tang Caoming, Luo Rui, Cheng Shaoge, Huang Baodong. Experimental study of seismic performance of low strength masonry walls reinforced with one-side cement mortar splint [J]. Journal of Building Structures, 2017, 38(10):157-167.

[8] R. Faria, J. Oliver, M. Cervera. A strain-based plastic viscous-damage model for massive concrete structures [J]. International Journal of Solids \& Structures, 1998, 35(14):15331558.

[9] J. Lee, G. L. Fenves and ASCE. Plastic damage model for cyclic loading of concrete structures. Journal of Engineering Mechanic, 1998, 124(8): 892-900.

[10] LI Zheng, LI Zhong-xian. A modified elastic damage constitutive model of concrete and its application [J]. Engineering mechanics 2011, 28(8):146-150.

[11] Mortezaei A, Kheyroddin A, Ronagh H R. Finite element analysis and seismic rehabilitation of a 1000-year-old heritage listed tall masonry mosque [J]. The Structural Design of Tall and Special Buildings, 2012, 21(5):334-353. 